\title{
Histology of the aortic media in dissecting aneurysms
}

\author{
GERALD MANLEY \\ From the Department of Pathology, The Radcliffe Infirmary, Oxford
}

SYNOPSIS Sections of the ascending aorta of 27 cases of dissecting aneurysm were compared histologically with the ascending aortae of 27 age- and sex-matched normotensive controls and 27 age- and sex-matched hypertensive controls. Elastic fragmentation and loss was seen to a similar degree in each series. Strip-like areas of muscle necrosis appeared to be associated as much with hypertension as with dissection. Two cases of dissecting aneurysm showed giant-cell aortitis. Mucopolysaccharide 'cysts' were seen more frequently, but by no means invariably, in the dissecting series. The only abnormality that distinguished the dissecting aortae from the normotensive and hypertensive controls with any constancy was an increase in the degree of metachromasia of the ground substance.

Cystic medial necrosis of the aorta was described by Erdheim in 1929, and became widely accepted as the cause of dissecting aneurysm. Doubt was cast on the simplicity of this concept in 1952, when Gore and Seiwert studied a large series of dissecting aneurysms. They found two quite different types of medial necrosis, one affecting the elastic laminae and predominant in younger patients, the other affecting muscle cells, and predominant in older patients. More recently, Hurley (1959) has denied that any characteristic histological abnormality accompanies aortic dissection.

One reason for this somewhat confused state of affairs is the lack of adequate control series, for the histological appearance of the aorta varies considerably with age, and indeed at different levels within the same aorta.

This paper presents a histological analysis of the ascending aorta in cases of dissecting aneurysm compared with age- and sex-matched normotensive and hypertensive controls.

\section{MATERIALS AND METHODS}

Twenty-seven cases of dissecting aneurysm examined at necropsy at the Radcliffe Infirmary, Oxford, over the past three years, together with 27 age- and sex-matched hypertensive controls, selected at necropsy, provided the material for this study. Transverse sections were taken from the ascending aorta $2 \mathrm{~cm}$. above the aortic valve, and fixed in buffered formol-saline for 10 days before embedding in paraffin. Sections were cut at $3 \mu$ and stained with haematoxylin and eosin, Azur-A, alcian

Received for publication 18 October 1963.
blue-P.A.S., and a combination of alcian blue, Verhoeff's $\vec{\theta}$ elastic, and Van Gieson's stain. Before staining, the sections were buffered at $\mathrm{pH} 6.8$ for one hour. The dissecting case (D), its normotensive control (C), and hypertensive control $(\mathrm{H})$ were batch-stained in every case. Testicular hyaluronidase digestion was carried out in normal saline for three hours at $37^{\circ} \mathrm{C}$., and papain digestion in phosphate buffer $p \mathrm{H} 6.5$ for five, 10, 15, and $30 \mathrm{~min}$. at $37^{\circ} \mathrm{C}$.

Each section was examined carefully under the light microscope. The Azur-A metachromasia, formation of mucopolysaccharide lakes, elastic fragmentation, muscle necrosis, and presence of inflammatory cellular infiltration in the tunica media were graded $0,1,2$, or 3 , according to degree.

\section{RESULTS}

The main results are summarized in the table.

METACHROMASIA The degree of Azur-A metachro-咅 masia of the aortic media showed considerable $\bar{N}$ variation in each of the three series. Some degree of $\sigma$ metachromasia was observed in every case, it being $N$ recorded as slight in $15(55 \%)$ of the normotensive aortae and $15(55 \%)$ of the hypertensive aortae. O Metachromasia was never less than moderate in the dissecting aortae. A high degree of metachromasia (graded 3 ) occurred in only one hypertensive aorta, $\stackrel{\oplus}{?}$ and was not observed at all in the normotensive 0 series. In contrast, a high degree of metachromasia was observed in eight $(30 \%)$ of the dissecting series. MUCOPOLYSACCHARIDE 'CYST' FORMATION It is by nog means uncommon to see small defects in the aortic 
TABLE I

HISTOLOGICAL OBSERVATIONS IN CONTROL, DISSECTING, AND HYPERTENSIVE AORTAE

\begin{tabular}{|c|c|c|c|c|c|c|c|c|c|c|c|c|c|c|c|c|c|c|c|c|c|c|c|c|c|c|c|}
\hline Case & 1 & 2 & 3 & 4 & 5 & 6 & 7 & 8 & 9 & 10 & 11 & 12 & 13 & 14 & 15 & 16 & 17 & 18 & 19 & 20 & 21 & 22 & 23 & 24 & 25 & 26 & 27 \\
\hline \multicolumn{28}{|l|}{ Normotensive Controls } \\
\hline Metachromasia & 2 & 2 & 1 & 1 & 2 & 1 & 1 & 1 & 2 & 2 & 2 & 1 & 2 & 1 & 1 & 2 & 2 & 1 & 2 & 1 & 1 & 1 & 2 & 1 & 2 & 1 & 1 \\
\hline Cysts & 0 & 1 & 0 & 1 & 1 & $\mathbf{0}$ & 0 & 1 & 0 & 1 & $\mathbf{0}$ & 0 & 0 & $\mathbf{0}$ & 0 & 1 & 1 & 0 & 0 & 0 & 0 & 0 & 1 & 0 & 0 & 0 & 0 \\
\hline Elastic fragmentation & 0 & 1 & 0 & 3 & 0 & 0 & 0 & 0 & 0 & 1 & 1 & $\mathbf{0}$ & 1 & 0 & 1 & 1 & 0 & 1 & 1 & 1 & 1 & 0 & 1 & 0 & 1 & 1 & 0 \\
\hline Muscle necrosis & 1 & $\mathbf{0}$ & $\mathbf{0}$ & 2 & 1 & $\mathbf{0}$ & 1 & 0 & 1 & 2 & 2 & 0 & 2 & 1 & 3 & 0 & 1 & 1 & 1 & 1 & 0 & 1 & 1 & 1 & 0 & 0 & 1 \\
\hline Cellular infiltration & $\mathbf{0}$ & $\mathbf{0}$ & $\mathbf{0}$ & 1 & $\mathbf{0}$ & 0 & 0 & 0 & 0 & 0 & 0 & 0 & $\mathbf{0}$ & 0 & 0 & 0 & 0 & 0 & 0 & 0 & 0 & 0 & $\mathbf{0}$ & 0 & 0 & 0 & 0 \\
\hline \multicolumn{28}{|l|}{ Dissecting Aneurysm } \\
\hline Metachromasia & 3 & 3 & 2 & 2 & 2 & 2 & 2 & 2 & 2 & 3 & 3 & 3 & 2 & 3 & 2 & 2 & 2 & 2 & 2 & 3 & 2 & 2 & 2 & 3 & 2 & 2 & 2 \\
\hline Cysts & 1 & 3 & 0 & 1 & 1 & 2 & 0 & 2 & 1 & 2 & 3 & 1 & 1 & 1 & 0 & 0 & 1 & 1 & 0 & 2 & 0 & 1 & 2 & 2 & 1 & 3 & 0 \\
\hline Elastic fragmentation & 1 & 3 & 0 & 3 & 1 & 1 & 0 & 3 & 2 & 3 & 2 & 2 & 1 & 1 & 1 & 2 & 1 & 1 & 0 & 2 & 1 & 1 & 1 & 1 & 0 & 0 & 0 \\
\hline Muscle necrosis & 1 & $\mathbf{0}$ & 1 & 2 & 1 & 1 & 2 & 1 & 2 & 1 & 1 & $\mathbf{0}$ & 1 & 2 & 1 & 2 & 1 & 2 & 2 & 3 & 0 & 1 & 1 & 2 & 1 & 0 & 1 \\
\hline Cellular infiltration & $\mathbf{0}$ & $\mathbf{0}$ & $\mathbf{0}$ & 3 & 0 & $\mathbf{0}$ & $\mathbf{0}$ & 0 & $\mathbf{0}$ & 3 & $\mathbf{0}$ & 0 & $\mathbf{0}$ & $\mathbf{0}$ & 0 & 0 & 0 & 0 & 0 & 0 & 0 & 0 & 0 & 0 & 0 & 0 & 0 \\
\hline \multicolumn{28}{|l|}{ Hypertensive Controls } \\
\hline Metachromasia & 1 & 2 & 1 & 1 & 1 & 2 & 2 & 2 & 1 & 3 & 2 & 2 & 1 & 1 & 2 & 2 & 1 & 1 & 2 & 2 & 1 & 1 & 1 & 1 & 1 & 2 & 1 \\
\hline Cysts & 0 & 0 & $\mathbf{0}$ & 0 & 0 & $\mathbf{0}$ & 0 & 2 & $\mathbf{0}$ & 1 & $\mathbf{0}$ & 0 & 0 & 0 & 0 & 2 & 0 & 0 & 1 & 0 & 0 & $\mathbf{0}$ & 0 & 1 & 0 & 0 & 0 \\
\hline Elastic fragmentation & 1 & $\mathbf{0}$ & $\mathbf{0}$ & 2 & 2 & 0 & $\mathbf{0}$ & 0 & $\mathbf{0}$ & 1 & $\mathbf{0}$ & 0 & 1 & 1 & 1 & 0 & 0 & 2 & $\mathbf{0}$ & 0 & 1 & 0 & 1 & 0 & 1 & 1 & 0 \\
\hline Muscle necrosis & 2 & 2 & 1 & 2 & 2 & 1 & 1 & 1 & 1 & 1 & 2 & 1 & 0 & 2 & 1 & 1 & 1 & 2 & 1 & 1 & 1 & 1 & 1 & 1 & 1 & $\mathbf{0}$ & 2 \\
\hline Cellular infiltration & $\mathbf{0}$ & 0 & 0 & 1 & $\mathbf{0}$ & 0 & 0 & $\mathbf{0}$ & $\mathbf{0}$ & $\mathbf{0}$ & 0 & $\mathbf{0}$ & $\mathbf{0}$ & 0 & $\mathbf{0}$ & 0 & 0 & 2 & 0 & 0 & 0 & 0 & $\mathbf{0}$ & 0 & 0 & 0 & 0 \\
\hline
\end{tabular}

media occupied by metachromatic ground substance. In this study, such small defects were ignored, and only large lesions, involving at least three of the parallel elastic laminae, were recorded. Such mucopolysaccharide-filled 'cysts' were observed very occasionally in the normotensive series, and slightly more frequently in the hypertensive series. In the dissecting series they were much more noticeable (Fig. 1), though not invariably present, and sometimes reached so great a size that they involved almost the entire thickness of the aortic media. Besides metachromatic and alcian blue-positive material, they usually contained a little disintegrating elastic tissue, disorientated muscle cells, and cytoplasmic fragments that appeared to be derived from the muscle cells. Indeed these cytoplasmic fragments were a constant feature of the mucopolysaccharide lakes.

ELASTIC LAMINAE Fragmentation of elastic laminae is frequently seen in appropriately stained sections of aortae; and some of this is undoubtedly due to a processing artefact. Areas of marked elastic fragmentation were seen rather more frequently in the dissecting series (Fig. 2), but mainly in areas of greatly increased metachromasia; away from these areas, the elastic laminae of dissecting aortae usually showed no significant fragmentation. Another very interesting change was that of medial tearing. In five of the dissecting series, large oblique or V-shaped tears were observed in the elastic laminae of the aortic media. One of these is illustrated in Figure 3. These tears were still bridged by muscle cells, and the broken ends of elastic laminae could be traced across them.

MUSCLE CELLS Two different types of change were seen. One was a strip-like necrosis, described by
Gsell in 1928. Small areas such as this were frequently seen, but more extensive areas of muscle necrosis, graded 2 in the table, were seen in only four $(15 \%)$ of the normotensive aortae, whereas they were recorded in eight $(30 \%)$ of the dissecting series and in eight $(30 \%)$ of the hypertensive series. The other type of change observed in the muscle cells was that of disorientation. In the dissecting series, where there was a great increase in the degree of metachromasia, or where lakes of mucopolysaccharide had been formed, complete disorientation of the muscle cells was observed. Particularly in relation to the mucopolysaccharide lakes, these disorganized muscle cells showed cytoplasmic fragmentation. Free fragments of cytoplasm were observed in many of the mucopolysaccharide lakes.

CELLULAR INFILTRATIONS In two cases of dissecting aneurysm, intense lymphocyte and plasma cell infiltration of the media was seen, together with the formation of giant cells around disintegrating elastic laminae (Fig. 4). In both cases the appearances were typical of giant-cell aortitis (Harrison, 1947).

ENZYME DIGESTION The metachromasia of the aortic ground substance was greatly reduced by testicular hyaluronidase, and that of the mucopolysaccharide lakes was completely destroyed. After digestion, the increased metachromasia of the dissecting series was no longer apparent. All metachromasia rapidly disappeared on papain digestion.

\section{DISCUSSION}

It is clear from this histological analysis that muscle necrosis is associated as much with hyper- 


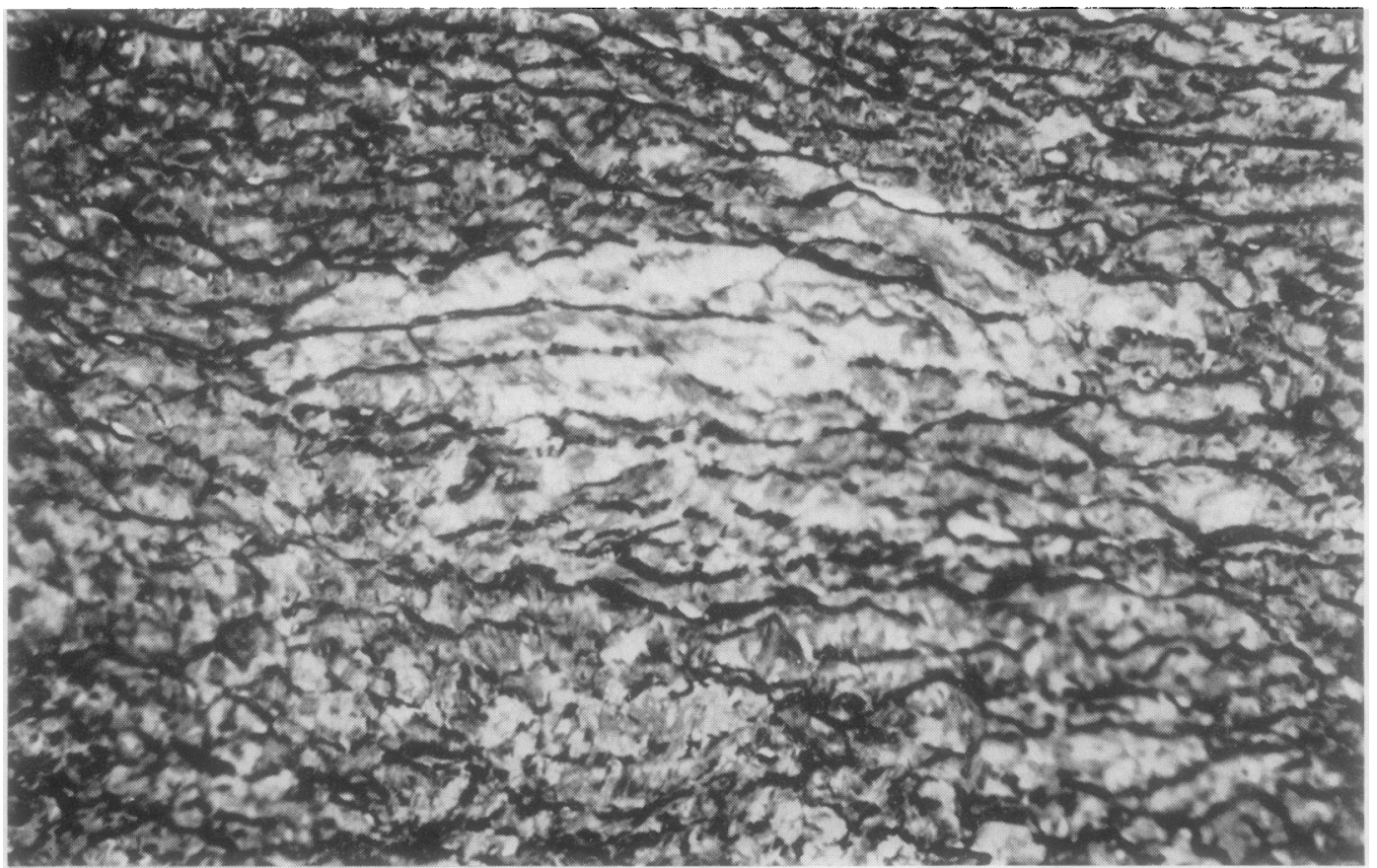

FIG. 1. Mucopolysaccharide 'cyst' in aortic media. This photomicrograph shows a small lesion. The elastic laminae are being pushed apart by an accumulation of highly metachromatic testicular hyaluronidase-labile material, and the interlaminar muscle cells appear to be degenerating. Case 2D. Alcian blue, Verhoeff and Van Gieson's stain $\times 150$.
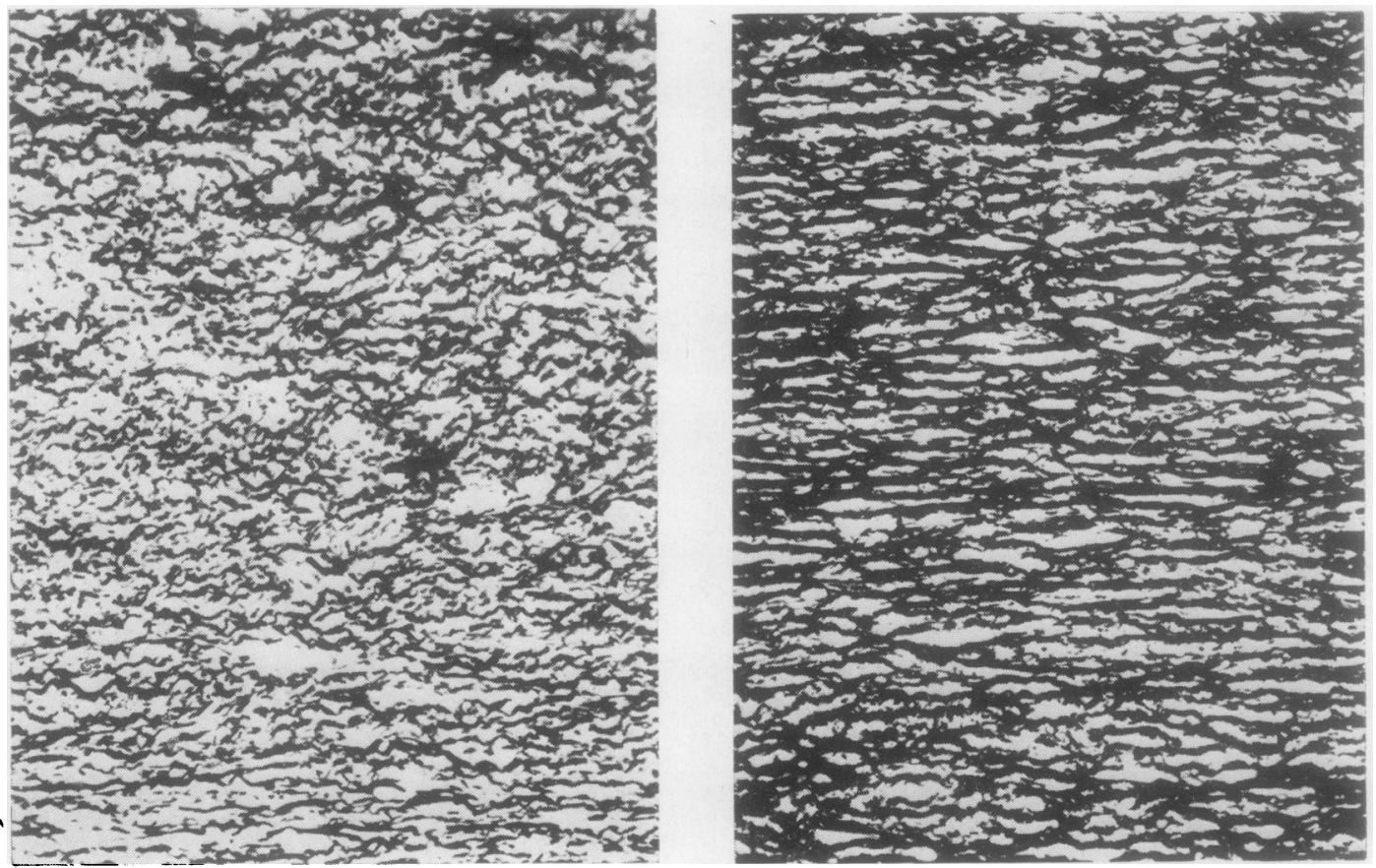

FIG. 2. Elastic fragmentation associated with an area of intense metachromasia in a dissecting aorta (right) with its normotensive control (left). Case $8 C$ and D. Alcian blue, Verhoeff and Van Gieson's stain $\times 70$. 


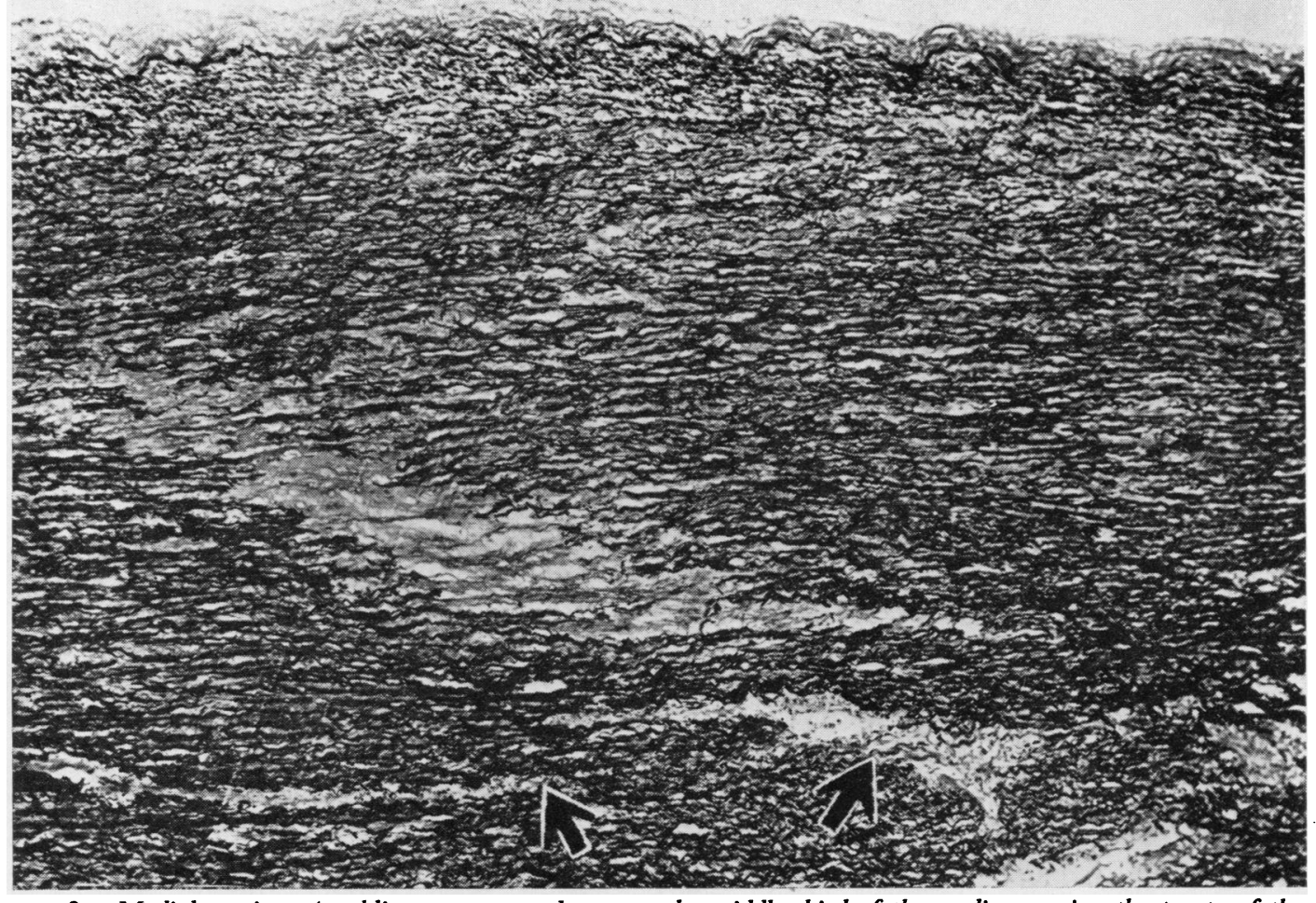

FIG. 3. Medial tearing. An oblique tear extends across the middle third of the media, nearing the tracts of the vasa vasorum in the outer third (arrowed). Case 23D. Alcian blue, Verhoeff and Van Gieson's stain $\times 50$.

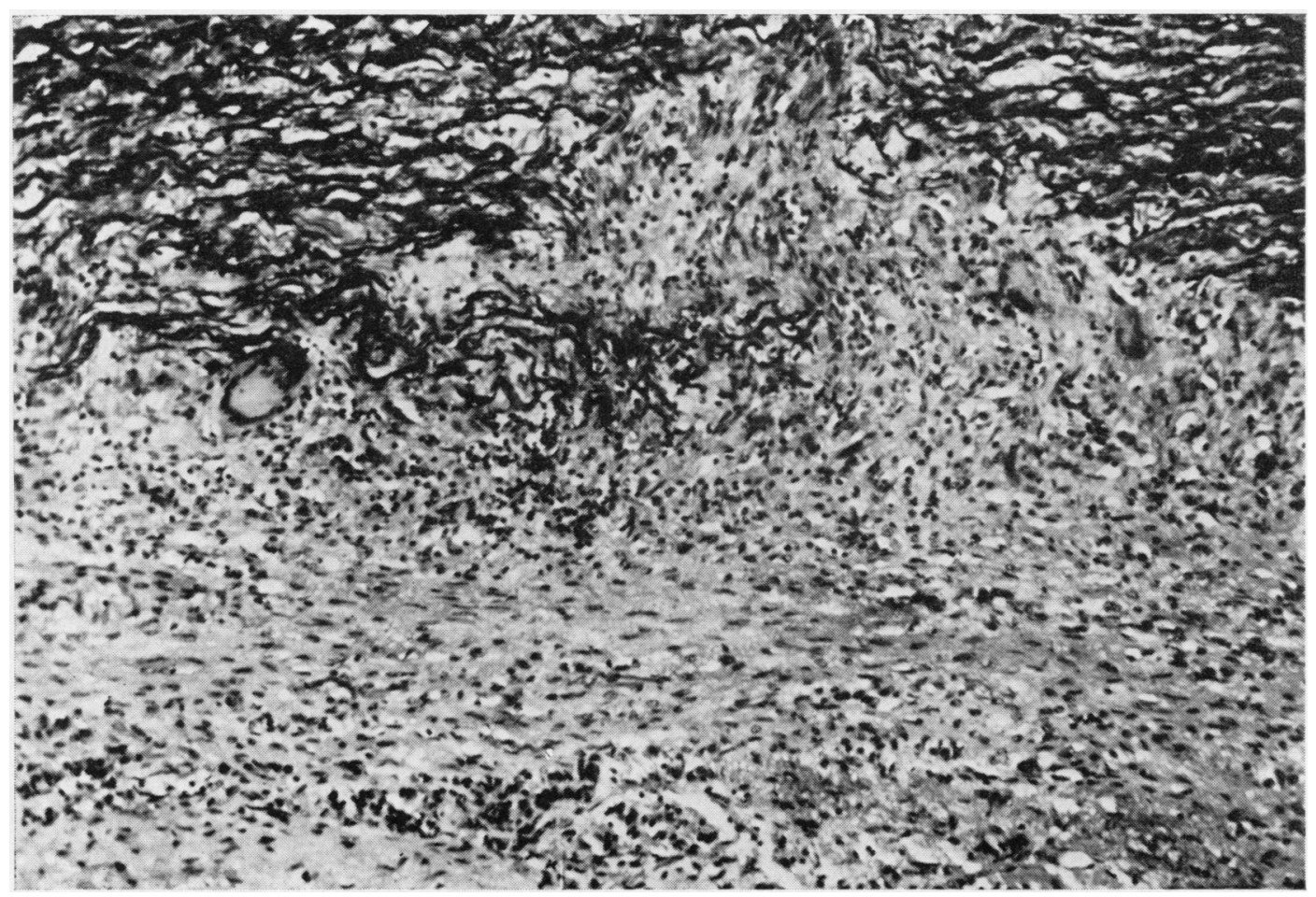

FIG. 4. Giant cell aortitis. A chronic inflammatory cellular infiltration is disrupting the media, and multi-nucleate giant cells are forming around disintegrating elastic laminae. Case 10D. Alcian blue, Verhoeff and Van Gieson's stain $\times 100$. 
tension as with dissecting aneurysm. This may well account for the finding of Gore and Seiwert (1952) that the aortae of cases of dissecting aneurysm in the higher age groups show muscle necrosis, since most patients with dissecting aneurysm over the age of $\mathbf{4 0}$ are hypertensive. Their observation that elastic damage is the most marked feature in younger patients cannot be confirmed here, since all patients were over 40 years. However, the fact that elastic fragmentation was observed in this series mainly in association with the highest degree of mucopolysaccharide accumulation suggested that it may be a secondary phenomenon.

The most constant feature of the dissecting series was a high degree of metachromasia and alcian blue positivity of the media. This suggested an increase in acidic mucopolysaccharide (Curran, 1960). Since the acidic mucopolysaccharides present in the aorta are hyaluronic acid, heparitin sulphate, and chondroitin sulphates B and C (Kaplan and Meyer, 1960) the removal of this increased metachromasia by testicular hyaluronidase suggested that it was due either to hyaluronic acid or chondroitin sulphate C. Another possibility was that acidic mucopolysaccharide groups, previously bound to protein, were being freed to give a higher degree of metachromasia in the dissecting aortae. It was thought that if this was the case, the action of papain on normal aorta would be, by digesting protein linked to acidic mucopolysaccharides, to increase the degree of metachromasia. In fact the reverse was observed, and this was possibly because the destruction of the mucopolysaccharide-protein complex released the acid mucopolysaccharide in soluble form.

The observation of medial tears in dissecting aortae is of some interest, as cases of dissecting aneurysm have been recorded in which no inter- ruption of the intima could be demonstrated (Gore and Seiwert, 1952; Hurley and Birrell, 1956). It is thought that these tears, by extending to the vascular outer third of the media, may cause an intramedial haematoma which, under a constant pounding in the aortic wall, may extend to form a dissecting aneurysm.

Dissection of aortae affected by giant-cell aortitis has been recorded previously (Magarey, 1950) but this disease can account for only a small proportion of cases of dissecting aneurysm. Syphilitic aortitis has been cited as a cause of dissecting aneurysm in the past (Shennan, 1934) but is probably an exceedingly rare cause now. Indeed the degree of fibrosis and thinning of the media in syphilitic aortitis would appear to favour simple rupture rather than dissection.

The selection of site and method of grading used here was unsuitable for an histological analysis of the degree of atheroma, since this is such a patchy lesion and tends not to affect the ascending aorta. Macroscopically, the dissecting aortae showed no more atheroma than the normotensive controls and rather less than the hypertensive controls.

I am grateful to Dr. A. H. T. Robb-Smith for advice during this study, and to Miss M. Reading for technical assistance.

\section{REFERENCES}

Curran, R. C. (1960). Biochem. Soc. Symp., no. 20, p. 32.

Erdheim, J. (1929). Virchows Arch. path. Anat., 273, 454.

Gore, I., and Seiwert, V. J. (1952). Arch. Path., 53, 121.

Gsell, O. (1928). Virchows Arch. path. Anat., 270, 1.

Harrison, C. V. (1947). J. clin. Path., 1, 197.

Hurley, J. V., (1959). Aust. Ann. Med., 8, 297.

$\longrightarrow$, and Birrell, J. H. W. (1956). Ibid., 5, 5.

Kaplan, D., and Meyer, K. (1960). Proc. Soc. exp. Biol. (N. Y.), 105, 78. Magarey, F. R. (1950). J. Path. Bact., 62, 445.

Shennan, T. (1934). Spec. Rep. Ser. med. Res. Coun. (Lond.), no. 193. 